\title{
COMPARISON OF GC AND HPLC FOR QUANTIFICATION OF ORGANIC ACIDS IN TWO JABOTICABA (Myrciaria) FRUIT VARIETIES
}

Gulab N. Jham*, Sergio A. Fernandes and Clerverson F. Garcia

Departamento de Química, Universidade Federal de Viçosa, 36570-000 Viçosa - MG, Brasil

Debra Palmquist

United States Department of Agriculture, Peoria, IL, 61604. USA

Recebido em 5/5/06; aceito em 15/2/07; publicado na web em 30/7/07

\begin{abstract}
Gas chromatography (GC) with trimethylsilyl derivative formation was compared to high-performance liquid chromatography (HPLC) for quantification of organic acids (OAs) in two jaboticaba (Myrciaria) fruit (pulp and pericarp) varieties (Sabará and Açu Paulista). Succinic and citric acids were the major OAs found in all the samples analyzed. Besides being much more tedious, the results obtained with GC were significantly lower than HPLC $(\mathrm{p}<0.05)$ when the data (acids, variety, two parts and flowering days) were considered together. The presence of both acids was confirmed by gas chromatography-mass spectrometry (GC-MS).
\end{abstract}

Keywords: jaboticaba; organic acids.

\section{INTRODUCTION}

Most jaboticaba species are distributed within the genus Myrciaria of the family Myrataceae. The short multi-stemmed indigenous trees are native to Brazil. The fruits grow rapidly within 40-46 days on the branches and when mature are round, about 2 $\mathrm{cm}$ in diameter, with the pericarp color ranging from red purple to black. The pulp is the major constituent of the fruit, tasting from sweet to slightly acidic ${ }^{1}$. The fruit is widely used in Brazil and mostly consumed in natura and to a smaller extent, as jelly and liqueur. Chemical composition of jaboticaba species has been very little investigated. Non-structural carbohydrates ${ }^{2}$, structural carbohydrates $^{3}$ and pigments ${ }^{4}$ were reported. Although no information is available in the literature on organic acids (OAs), they have been associated to fruit flavor. As a part of our program, we needed a quick method to quantify the OAs in jaboticaba pulp and pericarp in a large number of samples.

In principle, two methods could be used to identify and quantify jaboticaba OAs, i.e., gas chromatography (GC) and highperformance liquid chromatography (HPLC). The GC method appeared to be more interesting than the HPLC since it provides higher resolution and sensitivity. In addition, GC can be coupled to mass spectrometry (MS) capable of establishing unequivocal identification of compounds (this system is available in our laboratory). In this study, the GC and HPLC methods were compared to quantify the OAs in two jaboticaba fruit (pulp and pericarp) varieties (Sabará and Açu Paulista).

\section{EXPERIMENTAL}

\section{Materials and methods}

Gas chromatography with flame ionization detector (GC/FID) and gas chromatography-mass spectrometry (GC-MS)

A Shimadzu gas chromatograph (Kyoto, Japan, Model 17A) equipped with a FID detector, auto sampler and a system to

*e-mail: gulab@ufv.br accumulate data (Shimadzu, Kyoto, model CBM-101 with a computer-Pentium 133) was used in this study. A Shimadzu gas chromatograph-mass spectrometer (Kyoto, Japan, Model QP 5000) equipped with an auto sampler, on line mass spectra library (Wiley 229), direct insertion probe and a system to accumulate the data through a computer (Pentium 133) was used. With both the systems, fused silica capillary columns $(30 \mathrm{~m} \times 0.25 \mathrm{~mm}$ and $0.25 \mu \mathrm{m}$ film thickness) coated with the stationary phase DB-1 (Supelco, Bellefonte, PA) were used. The GC ovens were programmed from 100 to $150{ }^{\circ} \mathrm{C}$ at $5{ }^{\circ} \mathrm{C} / \mathrm{min}$ and from 150 to $280{ }^{\circ} \mathrm{C}$ at $3{ }^{\circ} \mathrm{C} / \mathrm{min}$. The FID and the GC-MS transfer line were maintained at $280{ }^{\circ} \mathrm{C}$. Nitrogen and $\mathrm{He}$ (flow rates 1.0/min) were the carrier gases for GC and GC-MS, respectively. The flow of the make up gas was 3.4 $\mathrm{mL} / \mathrm{min}$. In all cases, $1 \mu \mathrm{L}$ was injected in the splitless mode. The mass spectrometer was scanned from $\mathrm{m} / \mathrm{z} 40$ to $500 \mathrm{amu}$.

\section{Liquid chromatography}

The HPLC system consisted of a Rheodyne injector (Rohnert Pak, CA), with a $20 \mu \mathrm{L}$ loop, pump (GBC, Victoria, Australia, Model 1150), variable UV detector (Instrumentos CG, São Paulo, Brazil, model $480 \mathrm{C}$, set at $210 \mathrm{~nm}$ ), data-handling system-CBM-101 (Shimadzu, Kyoto, Japan). The column (Supelcogel C-610H, $250 \mathrm{x}$ $7.8 \mathrm{~mm}$ ) and the pre column (Supelcogel C-610H, $50 \times 7.8 \mathrm{~mm}$ ) were purchased from Supelco (Bellefonte, PA) and maintained at $40{ }^{\circ} \mathrm{C}$. The mobile phase $(0.4 \mathrm{~mL} / \mathrm{min})$ was $\mathrm{H}_{3} \mathrm{PO}_{4}: \mathrm{H}_{2} \mathrm{O}(1: 99, \mathrm{v} / \mathrm{v})$.

\section{Chemicals and standards}

The seven OAs (oxalic, citric, tartaric, malic, fumaric, quinic and succinic), and BSTFA [Bis(trimethylsilyl) trifluoroacetamide] were obtained from Sigma-Aldrich Chemicals (St. Louis, MO). Water was doubly distilled before use.

Solutions of the OAs ( $10 \mathrm{mg} / \mathrm{mL}$ in water) were prepared and 1 $\mathrm{mL}$ of each of the seven solutions was mixed to give a stock solution of $10 \mathrm{mg} / 7 \mathrm{~mL}(10 \mu \mathrm{g} / 7 \mu \mathrm{L})$ and used for GC and HPLC analyses.

\section{$G C$ studies}

For determination of the optimum reaction time for trimethylsilyl (TMS) derivative formation, stock solutions of OAs (250 $\mu \mathrm{L}$, containing $357.14 \mu \mathrm{g}$ of each OA) were lyophilized in a 5 
$\mathrm{mL}$ volumetric flask, residue reacted with $2 \mathrm{~mL}$ of BSTFA/ $0.5 \mathrm{~mL}$ of pyridine and heated for 30,60 and $120 \mathrm{~min}$ at $60{ }^{\circ} \mathrm{C}$. After each heating period, the solution was cooled, diluted to $5 \mathrm{~mL}$ with chloroform and $1 \mu \mathrm{L}$ (corresponding to $71.42 \mathrm{ng}$ of each $\mathrm{OA}$ ) was analyzed and the peak areas determined.

To produce succinic $(\mathrm{Su})$ and citric (Cit) acid calibration curves, aliquots $(35,25,20,15,10,5$ and $2.5 \mu \mathrm{L})$ of the lyophilized stock solutions (corresponding to 50, 35.71, 28.57, 21.42, 14.26, $7.14 \mu \mathrm{g}$, respectively) were reacted with $200 \mu \mathrm{L}$ of BSTFA $/ 50 \mu \mathrm{L}$ of pyridine, heated for $30 \mathrm{~min}$, diluted to $5 \mathrm{~mL}$ with chloroform and $1 \mu \mathrm{L}$ (corresponding to $10.00,7.01,5.71,4.26,2.86,1.49$ and $0.71 \mathrm{ng}$, respectively) analyzed by GC. The calibration curves (quantity injected versus area under the peak) and the $r$ value (correlation coefficient) were generated by the software with for each calibration curve.

\section{GC-MS studies}

The TMS derivatives prepared for GC studies were also utilized for GC-MS studies for determine the retention times $\left(t_{R}\right)$ and obtain the mass spectra of the standards.

\section{HPLC studies}

To produce calibration curves ( $\mathrm{Su}$ and $\mathrm{Cit}$ ), aliquots $(7,5,2.5$ and $1 \mathrm{~mL})$ of the stock solution $(10 \mathrm{mg} / 7 \mathrm{~mL})$, corresponding to $10,7.14,3.57$ and $1.49 \mathrm{mg}$, respectively were diluted to $10 \mathrm{~mL}$ with water and $20 \mu \mathrm{L}$ of each of these solutions corresponding to $20,14.29,7.14$ and $2.89 \mu \mathrm{g}$ were analyzed by HPLC The calibration curves (quantity injected versus area under the peak) and the $r$ value (correlation coefficient) were generated by the software with for each calibration curve.

\section{Validation of the methods (GC and HPLC)}

Before analyzing the samples, both methods were validated. Two standard solutions (5.714 and $1.428 \mathrm{ng}$ of each OA), two pulp samples (one of each variety-Sabará and Açu Paulista, obtained 20 days after flowering) and two pericarp samples (one of each varietySabará and Açu Paulista, obtained 20 days after flowering) were analyzed by GC (after TMS derivative formation) and HPLC and the relationship between the concentration and peak areas determined using the regression equation $y=a x+b$, where $\mathrm{a}$ and $\mathrm{b}$ are the regression coefficients, $x$ is the concentration of the analyte, $y$ the peak area. The correlation coefficient ( $r$ ) was computer obtained. To obtain the precision of the methods, the same solutions (standards and samples) were analyzed daily by GC and HPLC over a 10 day period.

\section{Statistical analyses}

The standard deviations (SD) and the \% relative standard deviation (RSD) computer calculated (Excel) were determined for peak areas. Two single factor analyses of variance (ANOVAs) were originally conducted, one for pulp and one for pericarp, comparing the GC and HPLC methods over the two acids identified, varieties, and days after flowering. If an F-test statistic was significant at $\mathrm{p} \leq .05$, the 2 methods were declared statistically different. Seventy two single-factor analyses of variance (ANOVAs) were also conducted, 36 for pulp and 36 for pericarp, comparing the GC and HPLC methods separately for each acid, variety, and days after flowering. If an F-test statistic was significant at $\mathrm{p} \leq .05$, the 2 methods were declared statistically different. Eight single-factor ANOVAs were performed, 4 for pulp and 4 for pericarp, comparing the GC and HPLC methods separately for each acid and variety, combining all days after flowering. If an F-test statistic was significant at $\mathrm{p} \leq .05$, the 2 methods were declared statistically different (Tables 6 to 8). All analyses were performed using SAS® PC Windows Version 9.1.3 software.

\section{Jaboticaba samples}

The fruits (about $2 \mathrm{~cm}$ in diameter) were collected from plants at the Universidade Federal de Viçosa on days 20, 30, 32, 34, 36, 38,40 and 42 after flowering and stored in a freezer at $-10{ }^{\circ} \mathrm{C}$. For analysis, the fruits were thawed to room temperature and the pericarp and pulp separated.

\section{Extraction, purification and identification of jaboticaba OAs}

For the GC procedure, a slightly modified method described ${ }^{5}$ previously was used. Briefly, $1 \mathrm{~g}$ of the pulp or $3 \mathrm{~g}$ of the macerated pericarp were extracted three times with water by agitation on a magnetic stirrer for $30 \mathrm{~min}$. The extracts were pooled, lyophilized, dissolved in methanol, purified by ion exchange chromatography, trimethysilyl (TMS) derivative formed and quantified by GC.

For HPLC, the tissues ( $1 \mathrm{~g}$ of the pulp or $3 \mathrm{~g}$ of the macerated pericarp) were extracted three times with $3 \mathrm{~mL}$ of distilled water by stirring on a magnetic stirrer for $15 \mathrm{~min}$. The extracts were combined, diluted to $10 \mathrm{~mL}$ with water, filtered through a membrane $(0.45 \mu \mathrm{m})$ and analyzed by HPLC. All analyses (GC and HPLC) were conducted in triplicates.

The TMS derivatives of OAs (TMS-OAs) and the OAs in the samples were identified by GC and HPLC, respectively, by comparing the $t_{R}$ with that of the standards. The presence of the TMS-OAs in the samples was also confirmed by GC-MS by comparing their $t_{R}$ and the mass spectra with standards. Identification of the TMS-OAs and the OAs was also conducted by comparing their MS with those of the database.

Percentage recovery of added Su and cit acids from jaboticaba samples

Known amounts $(1 \mathrm{mg})$ of standard $\mathrm{Su}$ and cit acids solutions were added to 16 samples previously quantified by GC and HPLC. Eight pulp samples (four of each variety-Sabará and Açu Paulista, obtained 20,30, 32 and 34 days after flowering) and eight pericarp samples (four of each variety-Sabará and Açu Paulista, obtained 20, 30, 32 and 34 days after flowering) were arbitrarily chosen. The \% recovery was calculated using the following formula: (conc. of added acid in spiked sample)/conc of endogenous acid + spike) $\mathrm{x}$ 100. All samples were analyzed in triplicates.

\section{RESULTS AND DISCUSSION}

\section{GC method}

Since no information was available in the literature on jaboticaba OAs, seven acids (oxalic, citric, tartaric, malic, fumaric, quinic and succinic), commonly found in fruits were chosen for initial identification. GC method was first developed for the identification of OAs. However, since GC does not permit unequivocal identification of compounds, we used GC-MS to overcome this limitation.

Preparation of derivatives is mandatory for the analysis of OAs by GC. Several types of derivatives can be utilized but we chose the trimethylsilyl (TMS) derivatives, as extensive literature was available ${ }^{6}$. Formation of the TMS derivatives by reacting lyophilized fruit extracts with BSTFA/pyridine was not satisfactory, since very complex chromatograms were obtained (data not presented). Purification of the extracts appeared to be necessary. Other methods i.e., electrohoretic/ ultrafiltration ${ }^{7}$ have been reported to clean up the OA extracts before TMS derivative formation. We decided to use the ion exchange method described $^{5}$ since no special equipments were needed. In addition, we decided to optimize TMS derivative formation by determining the GC 
response (peak area) after three reaction times $\left(0.5,1\right.$ and $\left.2 \mathrm{~h} 60{ }^{\circ} \mathrm{C}\right)$. The highest response was obtained after $0.5 \mathrm{~h}$ reaction time and all further reactions were conducted under this condition.

We next turned our attention to recoveries of OAs from two ion exchange columns. This was done by placing known quantities of standards on columns, elution, formation of TMS derivatives and quantification. These results were compared to those obtained without ion exchange columns. As it can be seen, reasonable recoveries were obtained for several organic acids but with the $\%$ RSD were quite large (Table 1). Initial experiments with jaboticaba indicated that the ethanol extraction ${ }^{5}$ provided significantly lower results $(60$ to $90 \%)$ as compared to water extraction (Table 2). Hence, water was used as the extraction solvent all quantifications.

Table 1. Percentage recovery ${ }^{\mathrm{a}}$ of standard organic acids after passing through two ion exchange columns, trimethylsilyl derivative (TMS) formation and quantification by gas chromatography

\begin{tabular}{lc}
\hline TMS derivative of organic acid & $\%$ Recovered \\
\hline Oxalic & $90 \pm 5.0$ \\
Succinic & $85 \pm 6.7$ \\
Fumaric & $91 \pm 5.2$ \\
Glutaric & $86 \pm 6.2$ \\
Malic & $85 \pm 6.8$ \\
Tartaric & $88 \pm 6.5$ \\
Citric & $88 \pm 9.0$ \\
Quinic & $87 \pm 6.4$
\end{tabular}

a Values are averages $\pm \% \operatorname{RSD}(\mathrm{n}=3)$

\section{Validation of the GC method}

Both Su and Cit exhibited an excellent linearity $(r)$ over the range tested with the correlation coefficient varying from 0.997 to 0.998 (Table 3). The GC method did not present a good precision, with \% RSD being quite large (Table 4). This was due to extensive sample manipulation necessary to quantify the OAs.

\section{Sample analysis and recovery of added standard OAs (GC)}

Results on OAs of 16 jaboticaba samples (8 pericarp and 8 pulp samples) and the results presented in Tables 5 and 6 . A typical chromatogram obtained with jaboticaba is in Figure 1. The chromatogram was clean; OAs base line separated containing essentially the peaks corresponding to the OAs. GC-MS analysis confirmed the presence of TMS derivatives of Cit, and Suc malic acids. When eight samples were spiked with standard solutions, recovery varied between 82 to $93 \%$ (Table 7). This was probably in part due to losses during ion exchange purification (Table 1).

\section{HPLC method}

The information obtained by GC and GC-MS helped simplify the HPLC method, since only the OAs previously identified were quantified. Although no information was available in the literature on the HPLC of jaboticaba OAs, it has been extensively used for OAs in foods ${ }^{8-13}$ and fruits ${ }^{14-25}$.

The procedure described ${ }^{11}$ to quantify coffee OAs with an ion exchange column with $\mathrm{H}_{2} \mathrm{~S} 04(0.009 \mathrm{~N})$ as the eluting solvent appeared to be interesting. However, extensive purification was needed before HPLC quantification with the recoveries varying from

Table 2. Comparison ${ }^{a}$ of extraction solvents (ethanol and water) for the quantification of organic acids by GC in two jaboticaba pulpvarieties Sabará and Açu Paulista

\begin{tabular}{|c|c|c|c|c|c|}
\hline \multirow[t]{2}{*}{ Sample } & \multirow[t]{2}{*}{ Extraction Solvent } & \multicolumn{2}{|c|}{$\begin{array}{c}\text { Citric acid } \\
(\mathrm{mg} / \mathrm{g}, \text { fresh weigh basis })\end{array}$} & \multicolumn{2}{|c|}{$\begin{array}{c}\text { Succinic acid } \\
(\mathrm{mg} / \mathrm{g}, \text { fresh weigh basis) }\end{array}$} \\
\hline & & Sabará & Sabará & Sabará & Açu Paulista \\
\hline \multirow[t]{2}{*}{1} & Water & $16.51 \pm 3.00$ & $61.56 \pm 13.88$ & $61.56 \pm 13.88$ & $46.52 \pm 3.66$ \\
\hline & Ethanol & $9.90 \pm 2.55$ & $6.15 \pm 1.77$ & $6.15 \pm 1.77$ & $5.52 \pm 1.98$ \\
\hline \multirow[t]{2}{*}{2} & Water & $17.58 \pm 2.00$ & $50.48 \pm 12.45$ & $50.48 \pm 12.45$ & $23.20 \pm 2.00$ \\
\hline & Ethanol & $10.76 \pm 3.22$ & $5.89 \pm 1.99$ & $5.89 \pm 1.99$ & $2.16 \pm 0.22$ \\
\hline \multirow[t]{2}{*}{3} & Water & $14.79 \pm 2.55$ & $30.64 \pm 3.25$ & $30.64 \pm 3.25$ & $13.95 \pm 3.04$ \\
\hline & Ethanol & $8.13 \pm 1.99$ & $3.23 \pm 1.99$ & $3.23 \pm 1.99$ & $1.18 \pm 1.99$ \\
\hline
\end{tabular}

${ }^{a}$ Values are averages $\pm \operatorname{RSD}(\mathrm{n}=3)$

Table 3. Relationship between citric and succinic acid concentrations and their peak areas by GC and HPLC

\begin{tabular}{|c|c|c|c|c|c|c|c|c|c|c|c|}
\hline \multicolumn{6}{|c|}{ GC } & \multicolumn{6}{|c|}{ HPLC } \\
\hline \multicolumn{3}{|c|}{ Citric acid } & \multicolumn{3}{|c|}{ Succinic acid } & \multicolumn{3}{|c|}{ Citric acid } & \multicolumn{3}{|c|}{ Succinic acid } \\
\hline $\mathrm{a}$ & $\mathrm{b}$ & $r$ & $\mathrm{a}$ & $\mathrm{b}$ & $r$ & $\mathrm{a}$ & $\mathrm{b}$ & $r$ & $\mathrm{a}$ & $\mathrm{b}$ & $R$ \\
\hline 1,501 & 23.66 & 0.998 & 1,524 & -24.38 & 0.998 & 2,491 & 153.8 & 0.999 & 2539 & -32.64 & 0.998 \\
\hline
\end{tabular}

$\mathrm{a}$ and $\mathrm{b}$ are the regression coefficients and $\mathrm{r}$ is the correlation coefficient for the two calibration curves (GC and HPLC)

Table 4. Precision of GC and HPLC methods after daily injection of standard solutions and four samples (two pulp and pericarp) over a 10day period

\begin{tabular}{lccccccccc}
\hline & \multicolumn{3}{c}{ Citric acid } & GC & \multicolumn{2}{c}{ Succinic acid } & \multicolumn{2}{c}{ Citric acid } & HPLC \\
& $\begin{array}{l}\text { Standard } \\
\text { deviation }\end{array}$ & $\begin{array}{c}\text { RSD } \\
(\%)\end{array}$ & $\begin{array}{c}\text { Standard } \\
\text { deviation }\end{array}$ & $\begin{array}{c}\text { RSD } \\
(\%)\end{array}$ & $\begin{array}{c}\text { Standard } \\
\text { deviation }\end{array}$ & $\begin{array}{c}\text { RSD } \\
(\%)\end{array}$ & $\begin{array}{c}\text { Standard } \\
\text { deviation }\end{array}$ & $\begin{array}{c}\text { RSD } \\
(\%)\end{array}$ \\
\hline Standard solution & 1.35 & 6 & 1.67 & 7 & 0.12 & 1 & 0.10 & 1 \\
Pericarp samples & 2.45 & 8 & 2.78 & 11 & 0.50 & 2 & 0.42 & 1 \\
Pulp samples & 1.99 & 9 & 2.66 & 10 & 0.34 & 2 & 0.33 & 1 \\
\hline
\end{tabular}


Table 5. Average concentrations ${ }^{\mathrm{a}}$ (mg/g, fresh weight basis) of organic acids by GC and HPLC in two jaboticaba pulp-varieties Sabará and Açu Paulista during development

\begin{tabular}{|c|c|c|c|c|c|}
\hline \multirow{2}{*}{$\begin{array}{l}\text { Days after } \\
\text { flowering }\end{array}$} & \multirow[t]{2}{*}{ Method } & \multicolumn{2}{|c|}{ Citric Acid } & \multicolumn{2}{|c|}{ Succinic Acid } \\
\hline & & Sabará & Açu Paulista & Sabará & Açu Paulista \\
\hline \multirow[t]{2}{*}{20} & GC & $16.51 \pm 7$ & $17.01 \pm 7 *$ & $61.56 \pm 9$ & $46.52 \pm 12$ \\
\hline & HPLC & $17.51 \pm 3$ & $19.89 \pm 0.5$ & $65.56 \pm 2$ & $49.52 \pm 1$ \\
\hline \multirow[t]{2}{*}{30} & $\mathrm{GC}$ & $17.58 \pm 7 *$ & $20.75 \pm 7$ & $50.48 \pm 9$ & $23.20 \pm 11$ \\
\hline & HPLC & $20.28 \pm 4$ & $22.75 \pm 2$ & $52.48 \pm 1$ & $25.20 \pm 1$ \\
\hline \multirow[t]{2}{*}{32} & GC & $14.79 \pm 9$ & $19.13 \pm 6$ & $30.64 \pm 10$ & $13.95 \pm 7 *$ \\
\hline & HPLC & $16.79 \pm 2$ & $19.93 \pm 1$ & $32.67 \pm 1$ & $16.25 \pm 0.3$ \\
\hline \multirow[t]{2}{*}{34} & $\mathrm{GC}$ & $5.58 \pm 9 *$ & $13.01 \pm 6 *$ & $17.37 \pm 9$ & $13.57 \pm 10 *$ \\
\hline & HPLC & $7.58 \pm 3$ & $15.01 \pm 3$ & $18.39 \pm 1$ & $16.57 \pm 4$ \\
\hline \multirow[t]{2}{*}{36} & GC & $7.39 \pm 8 *$ & $10.39 \pm 9 *$ & $9.87 \pm 8 *$ & $6.69 \pm 8 *$ \\
\hline & HPLC & $9.89 \pm 3$ & $12.99 \pm 4$ & $12.83 \pm 2$ & $8.59 \pm 1$ \\
\hline \multirow[t]{2}{*}{38} & $\mathrm{GC}$ & $10.59 \pm 7$ & $10.99 \pm 7$ & $12.04 \pm 8 *$ & $4.29 \pm 6 *$ \\
\hline & HPLC & $11.59 \pm 3$ & $10.79 \pm 3$ & $16.06 \pm 1$ & $6.29 \pm 1$ \\
\hline \multirow[t]{2}{*}{40} & $\mathrm{GC}$ & $3.94 \pm 9 *$ & $7.06 \pm 6$ & $2.56 \pm 9 *$ & $1.99 \pm 12$ \\
\hline & HPLC & $4.94 \pm 1$ & $7.60 \pm 3$ & $3.04 \pm 3$ & $2.26 \pm 3$ \\
\hline \multirow[t]{2}{*}{42} & $\mathrm{GC}$ & $7.44 \pm 7 *$ & $7.61 \pm 7$ & $11.33 \pm 6 *$ & $2.00 \pm 8$ \\
\hline & HPLC & $8.64 \pm 2$ & $7.61 \pm 3$ & $14.96 \pm 2$ & $2.26 \pm 2$ \\
\hline
\end{tabular}

${ }^{a}$ Values are averages $\pm \% \operatorname{RSD}(\mathrm{n}=3)$; *significantly lower at $\mathrm{p} \leq 0.05$.

Table 6. Average concentrations ${ }^{\mathrm{a}}$ (mg/g, fresh weight basis) of organic acids by GC and HPLC in two jaboticaba pericarp-varieties Sabará and Açu Paulista during development

\begin{tabular}{|c|c|c|c|c|c|}
\hline \multirow{2}{*}{$\begin{array}{l}\text { Days After } \\
\text { Flowering }\end{array}$} & \multirow[t]{2}{*}{ Method } & \multicolumn{2}{|c|}{ Citric Acid } & \multicolumn{2}{|c|}{ Succinic Acid } \\
\hline & & Sabará & Açu Paulista & Sabará & Açu Paulista \\
\hline \multirow[t]{2}{*}{20} & GC & $20.56 \pm 11$ & $13.36 \pm 8$ & $130.59 \pm 7 *$ & $88.09 \pm 10$ \\
\hline & HPLC & $21.98 \pm 44$ & $14.36 \pm 2$ & $150.51 \pm 1$ & $101.53 \pm 2$ \\
\hline \multirow[t]{2}{*}{30} & $\mathrm{GC}$ & $13.22 \pm 8 *$ & $23.18 \pm 10$ & $90.45 \pm 10$ & $83.09 \pm 10$ \\
\hline & HPLC & $17.06 \pm 3$ & $21.48 \pm 2$ & $94.05 \pm 2$ & $95.11 \pm 3$ \\
\hline \multirow[t]{2}{*}{32} & GC & $12.27 \pm 9 *$ & $22.99 \pm 12$ & $80.93 \pm 12$ & $58.09 \pm 8$ \\
\hline & HPLC & $15.27 \pm 2$ & $24.76 \pm 3$ & $84.35 \pm 2$ & $64.79 \pm 2$ \\
\hline \multirow[t]{2}{*}{34} & $\mathrm{GC}$ & $12.07 \pm 10 *$ & $21.03 \pm 9$ & $20.86 \pm 11 *$ & $39.99 \pm 8 *$ \\
\hline & HPLC & $14.57 \pm 3$ & $24.04 \pm 0.2$ & $24.62 \pm 2$ & $54.14 \pm 3$ \\
\hline \multirow[t]{2}{*}{36} & $\mathrm{GC}$ & $12.64 \pm 11 *$ & $20.31 \pm 10$ & $29.84 \pm 10$ & $30.84 \pm 10$ \\
\hline & HPLC & $15.64 \pm 4$ & $21.10 \pm 0.4$ & $32.28 \pm 2$ & $32.28 \pm 2$ \\
\hline \multirow[t]{2}{*}{38} & $\mathrm{GC}$ & $11.98 \pm 8 *$ & $30.33 \pm 11$ & $27.12 \pm 13 *$ & $39.70 \pm 12$ \\
\hline & HPLC & $16.85 \pm 4$ & $33.32 \pm 2$ & $33.14 \pm 1$ & $42.87 \pm 2$ \\
\hline \multirow[t]{2}{*}{40} & GC & $11.07 \pm 12 *$ & $17.70 \pm 9$ & $31.19 \pm 9 *$ & $50.10 \pm 10 *$ \\
\hline & HPLC & $14.03 \pm 1$ & $18.80 \pm 4$ & $39.01 \pm 3$ & $58.01 \pm 2$ \\
\hline \multirow[t]{2}{*}{42} & GC & $20.01 \pm 7$ & $25.41 \pm 10$ & $31.04 \pm 11$ & $43.45 \pm 7$ \\
\hline & HPLC & $22.08 \pm 1$ & $28.81 \pm 1$ & $34.97 \pm 3$ & $43.45 \pm 2$ \\
\hline
\end{tabular}

a Values are averages $\pm \% \operatorname{RSD}(\mathrm{n}=3)$; *significantly lower at $\mathrm{p} \leq 0.05$.

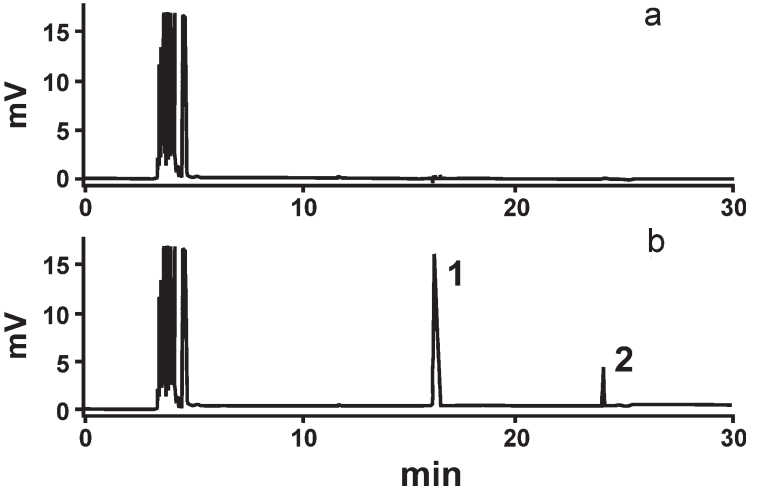

Figure 1. Typical chromatograms of blank (a) and TMS derivative (b) of the Sabará pulp extract (20 days after flowering). Peaks 1 and 2 were identified as the TMS derivatives of succinic and citric acids, respectively
1-100\%. The low recoveries were obviously unacceptable. Supelcogel C-610H ion-exchange column (sulfonated divinyl benzene-styrene co-polymer) used to quantify cheese OAs without purification of the water extract ${ }^{9}$, seemed interesting but their recovery was not reported. Coffee OAs were successfully quantified on this column with quantitative recoveries ${ }^{8}$. Hence, we decided to evaluate the Supelcogel C-610H ion-exchange column for the analysis of coffee OAs, addressing the question of recovery of OAs.

\section{Validation of the HPLC method}

Before attempting to quantify jaboticaba OAs, the method was validated and the results presented in Tables 3 and 4 . Both $\mathrm{Su}$ and Cit exhibited an excellent linearity $(r)$ over the range tested with the correlation coefficient varying from 0.997 to 0.998 (Table 3). The HPLC method presented a good precision, with \% RSD within 0.12 and $1.77 \%$, respectively, for the standards and the samples (Table 4). 
Sample analysis and recovery of added standard OAs (HPLC)

Having verified that the method was adequate, the OAs were quantified in 16 jaboticaba samples ( 8 pericarp and 8 pulp samples) and the results presented in Tables 5 and 6 . A typical trace is presented in Figure 2 and as it can be seen, a clean chromatogram was obtained. When eight samples were spiked with standard solutions, recovery varied between 94 to $99 \%$ (Table 8 ).

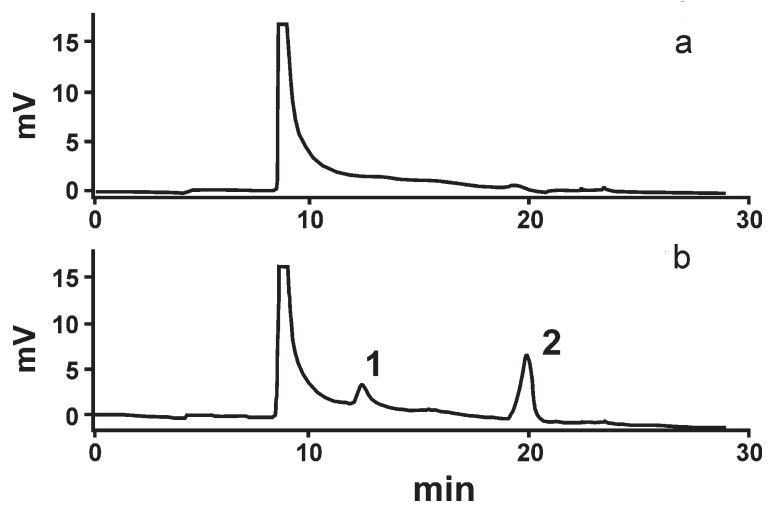

Figure 2. Typical HPLC chromatograms of blank (a) and water extract (b) of Açu Paulista pericarp (32 days after flowering). Peaks 1 and 2 were identified as citric acid and succinic acids, respectively

\section{GC $x$ HPLC methods}

Quantification results (GC and HPLC) of OAs in 16 jaboticaba samples are presented in Tables 5 and 6 , respectively. Both quantifications were conducted with the same extracts and hence the results could be compared.

Both of the single factor ANOVAs for pulp and pericarp showed no significant differences between the average concentration values of the GC and HPLC methods over all acids, varieties, and days after flowering (data not shown).
Sixteen of the 36 ANOVAs conducted on jaboticaba pulp, for each acid-variety-days after flowering combination, showed that the GC method was significantly lower than the HPLC method at $\mathrm{p} \leq .05$ (Table 5). Twelve of the 36 ANOVAs conducted on jaboticaba pericarp, for each acid-variety-days after flowering combination, showed that the GC method was significantly lower than the HPLC method at $\mathrm{p} \leq .05$ (Table 6). This was attributed, in part to relatively large errors in determinations by GC.

All eight single-factor ANOVAs, 4 for pulp and 4 for pericarp, comparing the GC and HPLC methods separately for each acid and variety, combining all days after flowering, showed the GC method measuring significantly lower concentration values than the HPLC method at $\mathrm{p} \leq .05$ (Tables 9 and 10)

Table 9. Average concentrations ${ }^{\mathrm{a}}(\mathrm{mg} / \mathrm{g}$, fresh weight basis) of organic acids by GC and HPLC in two jaboticaba pulp-varieties Sabará and Açu Paulista, over all development days

\begin{tabular}{lcccc}
\hline Method & \multicolumn{2}{c}{ Citric Acid } & \multicolumn{2}{c}{ Succinic Acid } \\
& $\begin{array}{c}\text { Sabará } \\
\mathrm{p}=.0003 *\end{array}$ & $\begin{array}{c}\text { Açu Paulista } \\
\mathrm{p}=.0161 *\end{array}$ & $\begin{array}{c}\text { Sabará } \\
\mathrm{p}<.0001 *\end{array}$ & $\begin{array}{c}\text { Açu Paulista } \\
\mathrm{p}=.0003 *\end{array}$ \\
\hline $\mathrm{GC}$ & $10.48 \pm 48$ & $13.24 \pm 38$ & $24.48 \pm 83$ & $14.03 \pm 103$ \\
HPLC & $12.15 \pm 43$ & $14.57 \pm 38$ & $27.00 \pm 77$ & $15.87 \pm 95$ \\
\hline
\end{tabular}

a Values are averages $\pm \% \operatorname{RSD}(n=3)$; *significantly lower at $\mathrm{p} \leq 0.05$.

Table 10. Average concentrations ${ }^{\mathrm{a}}$ (mg/g, fresh weight basis) of organic acids by GC and HPLC in two jaboticaba pericarp-varieties Sabará and Açu Paulista, over all development days

\begin{tabular}{lcccc}
\hline Method & \multicolumn{2}{c}{ Citric Acid } & \multicolumn{2}{c}{ Succinic Acid } \\
& $\begin{array}{c}\text { Sabará } \\
\mathrm{p}<.0001 *\end{array}$ & $\begin{array}{c}\text { Açu Paulista } \\
\mathrm{p}=.0339 *\end{array}$ & $\begin{array}{c}\text { Sabará } \\
\mathrm{p}=.0164 *\end{array}$ & $\begin{array}{c}\text { Açu Paulista } \\
\mathrm{p}=.0069 *\end{array}$ \\
\hline GC HPLC & $14.23 \pm 27$ & $21.79 \pm 24$ & $55.25 \pm 70$ & $54.17 \pm 38$ \\
& $17.18 \pm 18$ & $23.33 \pm 24$ & $61.62 \pm 69$ & $61.52 \pm 39$
\end{tabular}

${ }^{a}$ Values are averages $\pm \% \operatorname{RSD}(\mathrm{n}=3) ; *$ significantly lower at $\mathrm{p} \leq 0.05$.

Table 7. Percentage recovery ${ }^{\mathrm{a}}$ of organic acids from jaboticaba fruits spiked with standards (succinic and citric acids), ion exchange clean up, trimethylsilyl (TMS) derivative formation and quantification by gas chromatography

\begin{tabular}{lcccccccc}
\hline \multirow{2}{*}{$\begin{array}{l}\text { Days after } \\
\text { flowering }\end{array}$} & \multicolumn{2}{c}{ Sabará } & \multicolumn{2}{c}{ Citric Acid } & \multicolumn{3}{c}{ Succinic Acid } \\
& Pulp & Pericarp & Pulp & Pericarp & Pulp & Pericarp & Açu Paulista \\
Pulp & Pericarp \\
\hline 20 & $88 \pm 6$ & $88 \pm 8$ & $89 \pm 12$ & $89 \pm 12$ & $85 \pm 7$ & $83 \pm 7$ & $89 \pm 10$ & $94 \pm 7$ \\
30 & $83 \pm 8$ & $83 \pm 9$ & $93 \pm 6$ & $93 \pm 7$ & $93 \pm 7$ & $84 \pm 12$ & $88 \pm 7$ & $83 \pm 10$ \\
32 & $88 \pm 10$ & $88 \pm 9$ & $85 \pm 10$ & $87 \pm 10$ & $85 \pm 5$ & $86 \pm 10$ & $91 \pm 12$ & $87 \pm 8$ \\
34 & $90 \pm 8$ & $92 \pm 10$ & $93 \pm 12$ & $87 \pm 13$ & $89 \pm 12$ & $92 \pm 10$ & $94 \pm 7$ & $92 \pm 8$ \\
\hline
\end{tabular}

a Values are averages $\pm \% \operatorname{RSD}(\mathrm{n}=3)$

Table 8. Percentage recovery of organic acids obtained from jaboticaba fruits spiked with standards (succinic and citric acids) followed by HPLC quantification

\begin{tabular}{lcccccccc}
\hline Days after flowering & \multicolumn{2}{c}{ Sabará } & \multicolumn{2}{c}{ Citric Acid } & \multicolumn{3}{c}{ Sçuccinic Acid Paulista } & \multicolumn{2}{c}{ Sabará } & Açu Paulista \\
& Pulp & Pericarp & Pulp & Pericarp & Pulp & Pericarp & Pulp & Pericarp \\
\hline 20 & 99 & 99 & 99 & 97 & 98 & 97 & 97 & 97 \\
30 & 98 & 100 & 93 & 97 & 97 & 99 & 97 & 97 \\
32 & 98 & 98 & 97 & 99 & 98 & 98 & 99 & 98 \\
34 & 97 & 97 & 96 & 97 & 97 & 98 & 99 & 96 \\
36 & 97 & 98 & 98 & 99 & 93 & 97 & 95 & 96 \\
38 & 99 & 96 & 99 & 97 & 96 & 96 & 95 & 97 \\
40 & 96 & 99 & 94 & 99 & 99 & 99 & 94 & 95 \\
42 & 98 & 98 & 95 & 97 & 98 & 96 & 98 & 98 \\
\hline
\end{tabular}


Concentration of jaboticaba OAs by HPLC

\section{$\underline{\text { Succinic acid }}$}

Succinic acid was the principal acid in both varieties (Tables 5 and 6). In Sabará, its pulp concentration was the highest on day 20 after flowering; decreasing up to day 38 after flowering and tended to be random after that (Table 5). Similar tendency was observed in the pericarp with this concentration being higher than the corresponding value in the pulp on all days (Table 6). Similar tendencies were observed for Açu Palulista (Tables 5 and 6).

\section{Citric acid}

This was the second most abundant OA in jaboticaba (Tables 5 and 6). In Sabará, after an initial rise from day 20, its pulp concentration decreased up to day 36 becoming random after that. In Açu Paulitsa, also after an initial rise from day 20 after flowering, its concentration decreased up to day 38 , becoming constant after that. Pericarp citric acid concentrations in both the varieties were random.

\section{Malic acid}

The behavior presented by this acid was quite different as compared to citric and succinic acids. It was detected only in trace amounts in the variety Sabará, in both the pulp and pericarp only on days 20 and 30 after flowering.

\section{CONCLUSIONS}

The GC method for the quantification of coffee OAs was unsuitable for the quantification of jaboticaba OAs. The HPLC method was found to be very simple and reliable for OA quantification.

\section{ACKNOWLEDGEMENTS}

We would like to thank the Brazilian government funding agencies FAPEMIG and CNPq for the financial support. Scholarships to GNJ, SAF and CG from CNPq are also acknowledged. We would like to thank Prof. G. Vieira of Departmento de Fitotecnia/UFV for supplying the samples

\section{REFERENCES}

1. Wiltbank, W. J.; Chalfun, N. J.; Andersen, O.; Proc. Amer. Soc. Hortic. Sci. 1983, 27A, 57.

2. Barros, R. S.; Finger, F. L.; Magalhães, M. M.; Scientia Horticulturae 1996, 66, 209.

3. Barros, R. S.; Finger, F. L.; Magalhães, M. M.; Scientia Horticulturae 1996 66, 17.

4. Magalhães, M. M.; Barros, R. S.; Lopes, N. F.; J. Hortic. Sci. 1996, 71, 925.

5. Cambraia, J.; Galvani, F. R.; Estevão, M. M.; Sant'Anna, R.; J. Plant Nutr. 1983, 6, 313 .

6. Blau, K.; Halket, J.; Handbook of Derivatives for Chromatography, Wiley: Sussex, 1993.

7. Bähre, F.; Maier, G. H.; Fresenius J. Anal. Chem. 1996, 355, 190.

8. Jham, G. N.; Fernandes, S.; Garcia, C.; Phytochem. Anal. 2002, 13, 99.

9. Lues, J. F. R.; Botha, W. C.; Smit, E. J.; Int. Dairy J. 1998, 8, 959.

10. Morawski, J.; Food Technol. 1984, 38, 70.

11. Stegen, G. H. D.; van Duijn, J.; $12^{\text {th }}$ International Science Colloquim, Montreux, França 1987.

12. Tormo, M.; Izco, J. M.; J. Chromatogr., A 2004, 1033, 305

13. Peìrez-Ruiz, T.; Martiìnez-Lozano, C.; Tomaìs, V.; Martiìn, $J . ; J$. Chromatogr., A 2004, 1026, 57.

14. Jayaprakasha, G. K.; Sakariah, K. K.; J. Liq. Chromatogr. Relal. Technol. 2000, 23, 915 .

15. Romero, R. A.; Simal, L. J.; Vazquez, O. L.; Lopez, H. J.; Gonzales, C. M. J.; Dtsch. Lebensm.-Rundsch. 2000, 96, 142.

16. Perez, A. G.; Olias, R.; Espada, J.; Olias, J. M.; Sanz, C.; J. Agric. Food Chem. 1997, 45, 3545.

17. Bartolomé, A. P.; Ruperez, P.; Fuster, C.; J. Sci. Food Agric. 1996, 70, 475.

18. Lamikanra, O.; Inyang, I. D.; Leong S.; J. Agric. Food Chem. 1995, 43, 3026.

19. Ehlenfeldt, M. K.; Meredith, F. I.; Ballington, J. R.; Hortscience 1994, 29, 321.

20. Daood, H. G.; Biacs, P.; Czinkotai, B.; Hoschke, A.; Food Chem. 1992, 45,151 .

21. Hunter, J. J.; Visser, J. H.; Villiers, O. T.; Am. J. Enology Viti. 1991, 42, 237.

22. Morvai, M.; Ibolya, P.; J. Chromatogr. 1990, 520, 201.

23. Jayaprakasha, G. K.; Sakariah, K. K.; J. Chromatogr., A 1998, 806, 337.

24. Chinnici, F.; Spinabelli, U.; Riponi.; Amati. A.; J. Food Comp. Anal. 2005, 18,121 .

25. Alfawaz, M. A.; J. Food Comp. Anal. 2006, 19, 552. 